\title{
PHYSIOLOGICAL STRAIN IN THE HUNGARIAN MINING INDUSTRY: THE IMPACT OF PHYSICAL AND PSYCHOLOGICAL FACTORS
}

\author{
JÓZSEF VARGA' ${ }^{1}$ IMRE NAGY² ${ }^{2}$ LÁSZLÓ SZIRTES ${ }^{3}$, and JÁNOS PÓRSZÁSZ ${ }^{4,5}$
}

\author{
${ }^{1}$ Fizioergo Scientific Research Ltd., Budapest, Hungary \\ ${ }^{2}$ National Labour Office, Budapest, Hungary \\ Directorate of Labour and Occupational Safety, Division of Work Hygiene and Occupational Health \\ ${ }^{3}$ Metal-Carbon Ltd., Budapest, Hungary \\ ${ }^{4}$ University Medical School, Pécs, Hungary \\ Department of Pathophysiology \\ ${ }^{5}$ Los Angeles Biomedical Research Institute, Torrance, CA, USA \\ Rehabilitation Clinical Trials Center
}

\begin{abstract}
Objectives: The objectives of these investigations completed on workplaces in the Hungarian mining industry were to characterize the physiological strain of workers by means of work pulse and to examine the effects of work-related psychological factors. Material and Methods: Continuous heart rate (HR) recording was completed on 71 miners over a total of 794 shifts between 1987 and 1992 in mining plants of the Hungarian mining industry using a 6-channel recorder - Bioport (ZAK, Germany). The work processes were simultaneously documented by video recording along with drawing up the traditional ergonomic workday schedule. All workers passed health evaluation for fitness for work. The effects of different psychological factors (simulated danger, "instrument stress," presence of managers, and effect of prior involvement in accidents as well as different mining technologies and work place illumination) on the work pulse were evaluated. The statistical analysis was completed using SPSS software (version 13.0, SPSS Inc., USA). Results: The work-related physiological strain differed between work places with different mining technologies in groups of 12-18 workers. The work pulse was lowest in bauxite mining $(\Delta \mathrm{HR}=22 \pm 8.9 \mathrm{bpm})$ and highest in drift drilling in dead rock with electric drilling machine $(\Delta \mathrm{HR}=30 \pm 6.9 \mathrm{bpm})$. During sham alarm situation the work pulse was significantly higher than during normal activities with the same physical task $(\Delta \mathrm{HR}=36.7 \pm 4.8 \mathrm{bpm}$ vs. $25.8 \pm 1.6 \mathrm{bpm}, \mathrm{p}<0.001)$. When work was performed under different psychological stress, the work pulse was consistently higher, while improving the work place illumination decreased the physiological strain appreciably ( $\Delta \mathrm{HR}$ (median, 25-75 percentiles) $=23,20-26$ bmp vs. 28, 25-31.3 bpm, $\mathrm{p}<0.001$ ). Conclusions: Recording the heart rate during whole-shift work along with the work conditions gives reliable results and helps isolating factors that contribute to increased strain. The results can be used to implement preventive and health promotion measures.
\end{abstract}

Key words:

Work-related complex stress, Physiological strain, Health protection and promotion, Work pulse, Work-related accidents, Workplace illumination

Financial support: National Scientific Research Fund - project No. 430/1988 "Humanization in mining," project manager: József Varga, Dr. Dipl. Eng.; National Health Insurance Administration - project No. 21/1989 "Physiological measurements - prevention of health," project manager: József Varga, Dr. Dipl. Eng.; and Scientific Council on Health - project No. T-09008/1990 "The strain limits and characterization of the human work based on laboratory modeling and on-site physiological observations in order to assess the complex load," project manager: Prof. János Pórszász, M.D., Ph.D.

Received: February 21, 2015. Accepted: August 17, 2015.

Corresponding author: J. Pórszász, Rehabilitation Clinical Trials Center, Los Angeles Biomedical Research Institute at Harbor-UCLA Medical Center, 1124 W Carson St., Torrance CA 90502, USA (e-mail: porszasz@ucla.edu). 


\section{INTRODUCTION}

Work-related stress and its relationship with physiological strain under natural work conditions has been in the center of interest for a long time. A significant development has been achieved in the 1960s and 1970s when a method was developed [1-4] to assess the metabolic energy cost of work. This consists of taking detailed notes that are used to estimate the energy expenditure, taking into account work intensity and body position. The result made it possible to characterize the stress related to physical work quantitatively. The general recognition of this procedure resulted in developing standards [5] and the MET equivalents [6] as well as characterizing the work-related stress using the Borg's scale [7].

This method aimed at estimating the work stress, but it considered only the effects of physical work while largely ignored the effects of a series of environmental factors (climate, noise, lighting, etc.), the organizational and human elements of work (individual abilities, horizontal and vertical social connections of the worker at work).

The complex micro- (workplace), meso- (economic organizations) and macro-socioeconomic environment (home environment, effects of the family and society), the effects of work (physical work, work environment, organization as well as human relations) coexist and all contribute to the physiological strain experienced by the worker $[8,9]$.

The use of the up-to-date microelectronic-based methods in the field of occupational health and measurements of environmental factors (noise, climate and air quality) is a common practice, but studying the changes within the organism under work conditions and the strain related to complex stress lags behind the possibilities.

Several publications justify instrumental observations for studying work-related strain [10-14] but, considering the lack of adequate approaches, it was one of our purposes to develop methodology capable of adequate characterization of work-related stress and physiological strain relationship, including a range of psychological factors.

Apart from the physiological strain associated with heavy physical work and psychological stress, it is plausible that, due to dust exposure, work in the mines is likely to result in adverse respiratory effects. The coal miner's pneumoconiosis and silicosis are well-known, however, there was no similar effect on the lung function of miners in Australian bauxite mines [15]. The serum aluminum levels were also comparable to normal control subjects [16]. More importantly, however, in a similar geologic area in Hungary, Kovacs found that the thoron to radon concentration ratio was $>0.25$, suggesting that there might be an increased health risk [17].

In a systematic screening for cardiovascular limitations by ergometry, we found that the limitations occur roughly twice as often among uranium miners [18] and in coal miners [19] compared to the reference population. This suggests that heavy physical work itself might present increased risk factor for cardiovascular diseases.

In underground mining, the heavy physical work is being done under the stress attributable to partially unknown and difficult to predict natural forces. The work environment is entirely artificial in a confined space where the work largely depends on human interactions. Therefore, it is hypothesized that during the same physical work done under different psychological conditions, the heart rate increment (work pulse as the final common output) will potentially reflect these effects.

This work, therefore, is intended to report the results of our physiological measurements performed in the past decades among underground miners working in ever changing workplaces and in artificial life conditions while being exposed to complex stress. Our goal was to assess the complex stress-strain relationship in miners under their natural and completely artificial working conditions, and to demonstrate the usability of these results in characterizing the work tasks at workplaces and in promoting the fitness for work evaluations of workers. 


\section{MATERIAL AND METHODS}

\section{Subjects and mining plants}

A total of 71 miners were studied in 794 work-shifts across 5 mining plants over a five-year period (between 1987 and 1992). At the time of these investigations there were no regulations - specific to human research in workplaces - in effect in Hungary, however, all workers who were asked for cooperation, were informed about the aims and the involved procedures in the course of the examinations and consented to the procedures prior to each shift in which the heart rate sensors were applied. The study is based on observational investigations only and there were no interventions applied to the workers themselves.

The administration of the mining plant gave their approval for the observations and approved specifically doubling the work place illumination and cooperated in executing the sham-alarm situation in the mine. The study was conducted in accordance with the Helsinki Declaration as modified in 1983 and 1989. All data sets were de-identified for protection of personal information during the data analysis. All participants were active miners having valid fitness for work certificates released by the Occupational Health Service of the mining plants. The main demographic characteristics and the characteristics of the studied mining plants are presented in Table 1.

The work processes were documented by video recordings [20-23], which were used for taking concomitant traditional pencil and paper notes to record the time stamps according to switching work-tasks during the working day. The characteristic environmental conditions (temperature, humidity, illumination) at the workplaces are also listed in Table 1. The mining work and its conditions usually change from shift to shift, therefore to get an "overall"characteristic picture of the work-related stress and physiological strain we recorded multiple shifts on each observed person while under similar technologies and work tasks. Due to work organization and scheduling

Table 1. Demographics of the workers and characteristics of the studied workplaces

\begin{tabular}{|c|c|c|c|c|c|}
\hline \multirow[b]{2}{*}{ Characteristics } & \multicolumn{5}{|c|}{ Mining plant } \\
\hline & $\begin{array}{l}\text { Halimba } \\
\text { (bauxite) }\end{array}$ & $\begin{array}{l}\text { Ajka } \\
\text { (coal) }\end{array}$ & $\begin{array}{c}\text { Nyírád } \\
\text { (bauxite) }\end{array}$ & $\begin{array}{c}\text { Csabpuszta } \\
\text { (bauxite) }\end{array}$ & $\begin{array}{l}\text { Halimba } \\
\text { (bauxite) }\end{array}$ \\
\hline Studied period & $1987-1988$ & 1988-1989 & 1989 & 1990 & 1991-1992 \\
\hline \multicolumn{6}{|l|}{ Workers } \\
\hline miners $[\mathrm{n}]$ & 12 & 18 & 12 & 15 & 14 \\
\hline shifts [n] & 201 & 238 & 110 & 123 & 122 \\
\hline age [years] $(\mathrm{M} \pm \mathrm{SD})$ & $39.0 \pm 9.3$ & $33.3 \pm 7.7$ & $39.1 \pm 7.8$ & $36.2 \pm 8.6$ & $37.5 \pm 9.7$ \\
\hline working in mine [years] $(\mathrm{M} \pm \mathrm{SD})$ & $16.4 \pm 4.6$ & $11.3 \pm 9.3$ & $18.4 \pm 8.1$ & $10.6 \pm 8.8$ & $16.0 \pm 10.5$ \\
\hline weight $[\mathrm{kg}](\mathrm{M} \pm \mathrm{SD})$ & $76.7 \pm 9.9$ & $74.7 \pm 10.1$ & $81.6 \pm 11.5$ & $81.1 \pm 11.0$ & $84.3 \pm 16.9$ \\
\hline height $[\mathrm{cm}](\mathrm{M} \pm \mathrm{SD})$ & $171.3 \pm 4.9$ & $171.8 \pm 8.1$ & $171.2 \pm 4.8$ & $174.4 \pm 7.0$ & $174.5 \pm 7.1$ \\
\hline \multicolumn{6}{|l|}{ Workplace } \\
\hline temperature $\left[{ }^{\circ} \mathrm{C}\right]$ & $16-18$ & $15-17$ & $13-14$ & 17 & $15-16$ \\
\hline relative humidity [\%] & $94-95$ & $82-84$ & $95-96$ & 88 & 93 \\
\hline noise level $[\mathrm{dB}]$ & $70-110$ & $65-85$ & $80-98$ & $93-98$ & $88-109$ \\
\hline illumination [Lux] & $8-15$ & $10-14$ & $14-20$ & $15-35$ & $10-15$ \\
\hline
\end{tabular}

M - mean; SD - standard deviation. 
issues, the observed number of workers varied on a daily basis during our observations. Therefore, the number of workers and the observed shifts varied. To overcome the resulting potential statistical difficulties, we observed several workers over a number of shifts.

Before the work-shift had started, resting heart rate was recorded in lying or in sitting position at the time of mounting the sensors for recording the physiological variables.

\section{Measurements}

The measurements of the physiological variables were performed using a multichannel Bioport (ZAK, Germany) recorder at the workplace. The six channels were individually programmed to collect heart rate (HR), core temperature (Tc), and other signals that are not presented in the current report. The recordings were in $30 \mathrm{~s}$ timeaverage bins. In this report we discuss mainly the results collected in the heart rate channel.

The workers taking part in the physiological measurements at workplace also underwent symptom-limited incremental exercise tests on treadmill according to the Bruce protocol [24]. The goal of the exercise tests was to exclude any clinically significant exercise-limiting condition. The maximal achieved heart rate was used to calculate the maximal heart rate reserve $\left(\mathrm{HR}_{\max }-\mathrm{HR}_{\text {rest }}\right)$. The heart rate increment above the resting value, i.e., the "work pulse" $\left(\Delta \mathrm{HR}=\mathrm{HR}_{\text {work }}-\mathrm{HR}_{\text {rest }}\right)$ was calculated and evaluated as physiological strain during the work processes. Relative strain was calculated as $\Delta \mathrm{HR}$ in percentage of maximal heart rate reserve.

\section{Statistical methods}

Statistical analysis included descriptive statistics (mean, 95\% confidence intervals, variance, standard deviation) and normality was tested using standard SPSS (version 13.0, SPSS Inc., USA) procedures.

Statistical independence was tested by Student's t-test. Associations between variables were tested by correlation analysis.
Parametric statistical tests were completed if the data passed the normality (Shapiro-Wilk) test, otherwise non-parametric tests (rank sum test by Mann-Whitney U statistic) were conducted. Multiple comparisons were performed by Friedman ANOVA on ranks with post hoc multiple comparison procedures by Tukey's test. The comparisons were based on the full data set including effects by individuals, shifts, working technologies and by different working processes. Significance was set at $\mathrm{p}<0.05$.

\section{RESULTS}

\section{Characteristic changes in heart rate} and core temperature during a whole shift

A typical work shift with an original recording of heart rate and core temperature is illustrated in Figure 1. In this shift in a bauxite mine, the first 30-40 min segment during which the worker travels to the effective work place is relatively "silent." The heart rate hovers between 85-95 bpm while the core temperature starts to rise. During the whole shift, there are three high activity-related bursts. During these periods, the heart rate fluctuates between $90 \mathrm{bpm}$ and $140 \mathrm{bpm}$.

After the first high-activity period, there is about $40 \mathrm{~min}$ of low activity period, during which the heart rate recovers, but to about $10 \mathrm{bpm}$ above the baseline value recorded at the start of the work shift. Remarkably, after the second high-activity period, during which the heart rate reaches again $140 \mathrm{bpm}$, it recovers to an even higher value (about $115 \mathrm{bpm}$ ). Notably, the core temperature follows the heart rate changes with an appreciable delay and also recovers to higher baseline values after each activity bout (Figure 1). Meanwhile, both heart rate and core temperature changes exceed the recommended maximal values for the whole shift (marked with horizontal lines in Figure 1).

Importantly, the heart rate during recovery after the second burst of activity does not return to a level below the recommended value (i.e., $110 \mathrm{bpm}$ ) for the whole shift. 


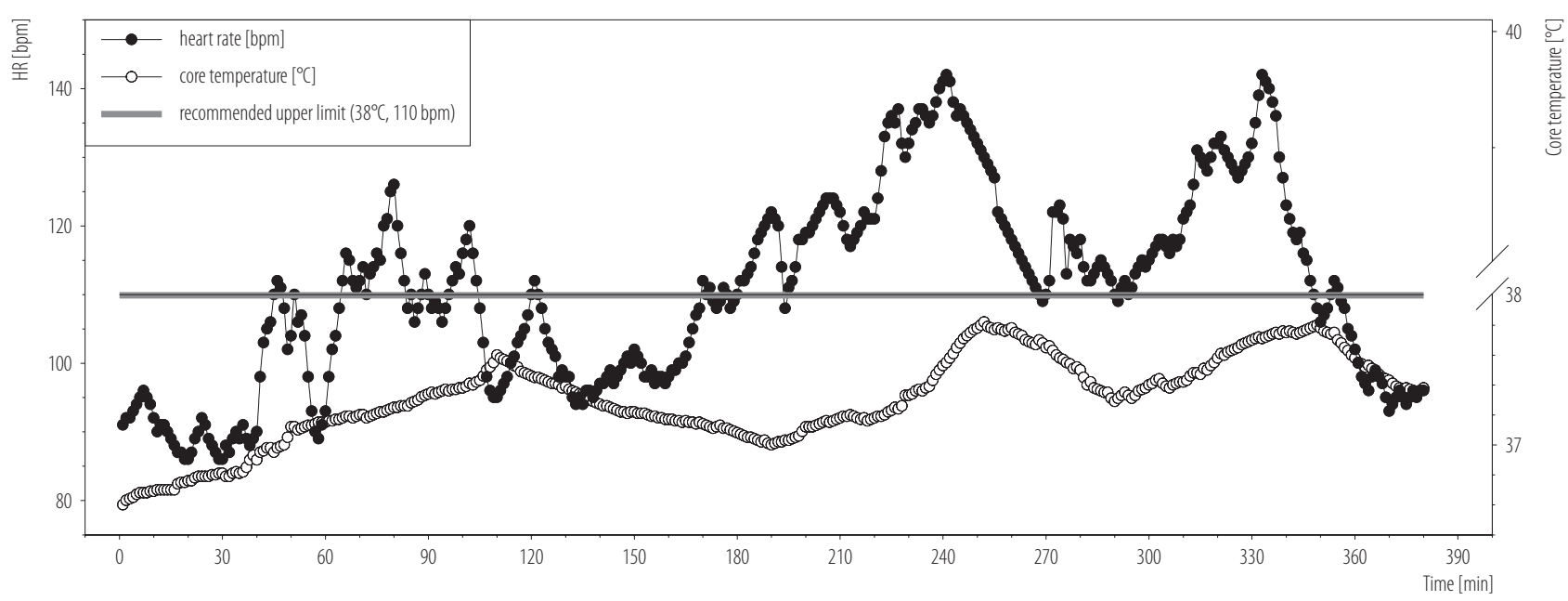

Data points are average values over $1 \mathrm{~min}$.

Fig. 1. Changes of heart rate (HR) and core temperature of a miner working in an underground bauxite mine during an 8-h work shift

The cumulative upward trend in both variables reflects an increase in physiological strain over time in the work shift. These physiological changes reflect continually increasing physiological strain in a complex work process.

\section{The use of work pulse ( $\triangle H R)$}

The resting heart rate is highly variable within each individual, depending on the actual conditions (fitness, stress level, lifestyle, etc.). The heart rate response to work-related physical and psychological influences is also

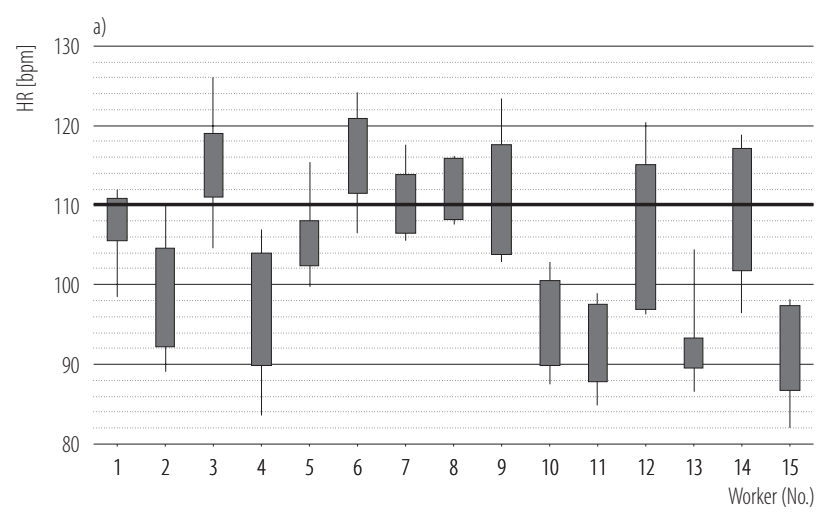

variable, subject to cardiovascular fitness, health condition, environmental and psychological stress. Therefore, we sought investigating whether using the work pulse $(\Delta \mathrm{HR})$ instead of the absolute heart rate during work activities would be a more reliable index of work-related strain assessments.

Figure 2 shows the significant individual variations of heart rate (HR) measured during work under identical mining technologies in 123 work shifts of 15 miners. Individual conditions are characterized by resting heart rate $\left(\mathrm{HR}_{0}\right)$, and

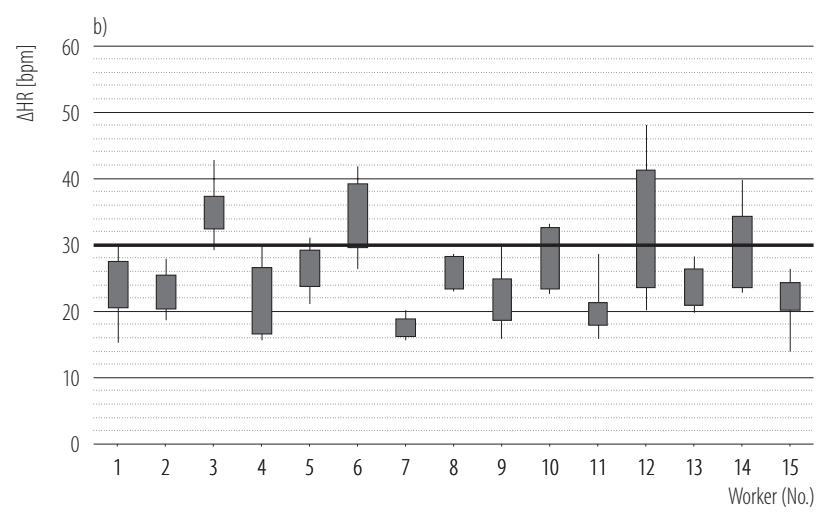

Box plots - quartiles and whiskers with $5 \%$ and $95 \%$ confidence intervals. Horizontal line - the recommended limits over an 8-h shift (30 bpm and $110 \mathrm{bpm}$ for the $\Delta \mathrm{HR}$ and HR, respectively).

Fig. 2. Heart rates (HR) (a) and work pulse $(\Delta \mathrm{HR})(\mathrm{b})$ of 15 miners in 8 shifts per person 
the reaction to work stress is reflected by the increment of heart rate over the resting value ("work pulse," $\Delta \mathrm{HR}$ ).

Very frequently, the average heart rate of the workers might be the same, however the corresponding work pulse can be appreciably different. In some cases, the absolute heart rate is relatively high and similar while the work pulse is remarkably different (workers No. 3, 7, 8, 9 and 14, Figure 2). In contrast, in other cases, the absolute heart rate is relatively low, but the work pulse shows high level of physiological strain (workers No. 10 and 13). In some cases both heart rate and work pulse are high (worker No. 3 ). These observations support the view that the work pulse is a better descriptor of work-related physiological strain. The actual relationship between the heart rate and the maximal heart rate achieved during an incremental exercise test defines the "relative strain." Figure 3 illustrates the differences between the two measures of physiological strain (work pulse and relative strain) when the work-related absolute heart rates are virtually identical. The difference in work pulse in these two subjects is statistically significant and there is a tendency in relative strain to be different,

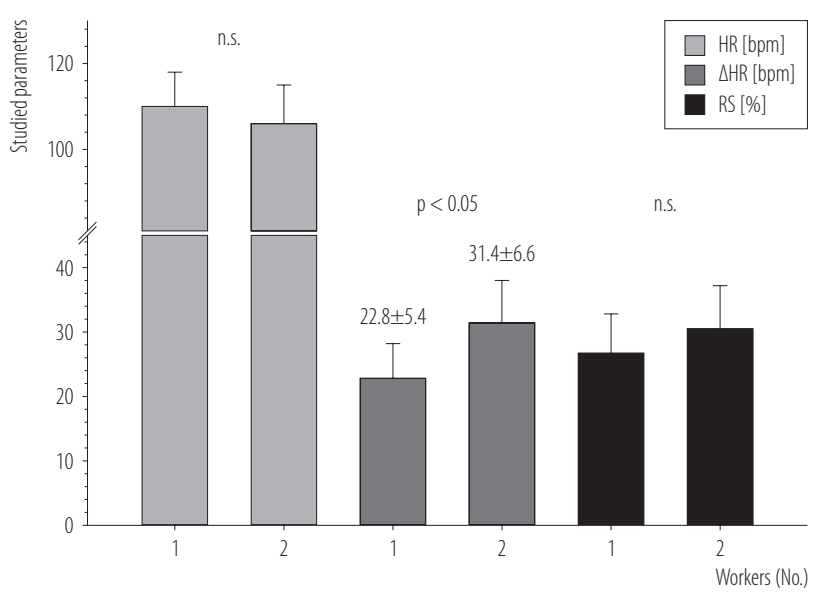

Relative strain $=\Delta \mathrm{HR} /\left(\mathrm{HR}_{\max }-\mathrm{HR}_{\text {rest }}\right) \times 100$

(where: $\mathrm{HR}_{\max }$ - the maximal heart rate reached in an incremental exercise test).

n.s. - not statistically significant.

Fig. 3. Heart rate (HR), work pulse ( $\Delta \mathrm{HR})$ and relative strain $(\mathrm{RS})$ of 2 miners during 9-10 shifts with the same average HR but this did not achieve statistical significance (average heart rates are 111 bpm in workers No. 9 and No. 14, while $\Delta \mathrm{HR}$ are $22.8 \mathrm{bpm}$ and $31.4 \mathrm{bpm}$ ( $\mathrm{p}<0.05)$, respectively). Mean values are from 10 work-shifts in both subjects during the same work activities. These differences demonstrate that use of work pulse is preferable over the absolute heart rate to characterize work-related physiological strain.

Notably, these differences are apparent in the same work processes. In 15 miners, working in drift drilling in a bauxite mine (Photo 1) the resting heart rate varied between $59 \mathrm{bpm}$ and $101 \mathrm{bpm}$, while it was between $82 \mathrm{bpm}$ and 129 bpm during work. However, these differences largely disappeared when we considered changes in work pulse (Table 2); the mean of which varied only between $20 \mathrm{bmp}$ and $36 \mathrm{bpm}$. On the other hand, the significant positive correlation between the work pulse and absolute heart rate had a relatively low explained variance $\left(\mathrm{R}^{2}=0.339, \mathrm{p}=0.0228\right)$ with an insignificant power at $\alpha=0.05$ of 0.635 (n.s.). This signals that the work pulse behaves largely independently of the absolute heart rate. In general, the physiological strain changes by the hour of the work-shift as illustrated by both the absolute heart rate and the work pulse of workers at the same workplace (Figure 4). Hourly changes in HR and work pulse indicate that

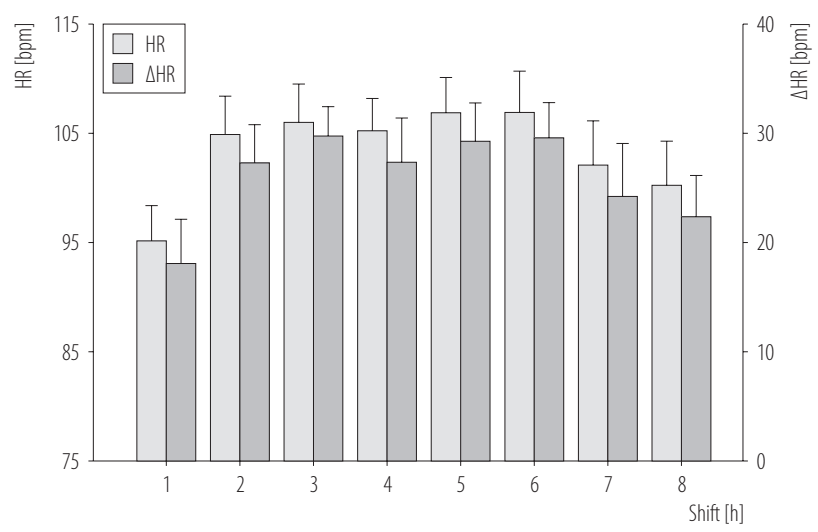

The overall mean values: $\mathrm{HR}=103 \pm 11 \mathrm{bpm}, \Delta \mathrm{HR}=26 \pm 9.6 \mathrm{bpm}$.

Fig. 4. Hourly changes of heart rate (HR) and work pulse $(\Delta \mathrm{HR})$ during a shift during 124 shifts of 15 miners from the same exploratory tunneling 
Table 2. Individual physiological strain data at an exploratory tunneling

\begin{tabular}{|c|c|c|c|c|c|c|c|}
\hline \multicolumn{2}{|c|}{ Worker } & \multirow{3}{*}{$\begin{array}{c}\text { Observations } \\
{[\mathrm{n}]}\end{array}$} & \multirow{2}{*}{\multicolumn{2}{|c|}{$\begin{array}{c}\text { HR } \\
{[\mathrm{bpm}]}\end{array}$}} & \multirow{3}{*}{$\begin{array}{c}\mathrm{HR}_{0} \\
{[\mathrm{bpm}]} \\
\text { (min.-max) }\end{array}$} & \multirow{2}{*}{\multicolumn{2}{|c|}{$\begin{array}{c}\Delta \mathrm{HR} \\
{[\mathrm{bpm}]}\end{array}$}} \\
\hline \multirow{2}{*}{ No. } & \multirow{2}{*}{$\begin{array}{c}\text { age } \\
\text { [years] }\end{array}$} & & & & & & \\
\hline & & & $\mathrm{M}$ & $\min .-\max$ & & $\mathrm{M}$ & $\min .-\max$ \\
\hline 1 & 46 & 7 & 99 & 89-111 & $63-86$ & 24 & 19-29 \\
\hline 2 & 38 & 10 & 106 & $95-112$ & $72-94$ & 24 & $14-32$ \\
\hline 3 & 38 & 10 & 96 & $82-108$ & $62-79$ & 22 & $16-33$ \\
\hline 4 & 35 & 10 & 115 & $100-129$ & $67-93$ & 36 & 29-44 \\
\hline 5 & 26 & 9 & 106 & 98-119 & 74-90 & 27 & $21-32$ \\
\hline 6 & 44 & 4 & 112 & 106-119 & $82-92$ & 26 & $22-30$ \\
\hline 7 & 33 & 8 & 118 & $106-125$ & $75-94$ & 35 & $26-43$ \\
\hline 8 & 26 & 9 & 111 & 105-118 & $87-99$ & 20 & $16-21$ \\
\hline 9 & 35 & 9 & 111 & $103-127$ & 82-101 & 23 & $16-34$ \\
\hline 10 & 29 & 8 & 95 & 93-104 & $63-70$ & 29 & $23-34$ \\
\hline 11 & 48 & 8 & 93 & 84-99 & $65-79$ & 20 & $15-32$ \\
\hline 12 & 29 & 10 & 108 & $97-125$ & $67-79$ & 34 & 19-49 \\
\hline 13 & 44 & 7 & 93 & $83-107$ & 59-78 & 24 & $21-29$ \\
\hline 14 & 52 & 10 & 111 & $90-120$ & $66-90$ & 32 & $22-42$ \\
\hline 15 & 26 & 4 & 92 & $82-98$ & $64-74$ & 22 & $14-27$ \\
\hline Total & & 123 & 105 & $82-129$ & 59-101 & 29 & 14-49 \\
\hline
\end{tabular}

$\mathrm{HR}$ - heart rate during work; $\mathrm{HR}_{0}$ - heart rate at rest; $\Delta \mathrm{HR}$ - work pulse; $\mathrm{M}$ - mean; min. - minimal value; max - maximal value.

Mean age of workers: 36.6 years.

strain is increasing during the first 6 hours of the shift (with the exception of lunch break in the 4th hour).

Using the work pulse, we characterized 23 different work tasks along with their cumulative durations. Depending on the heart rate increments, the work tasks can be categorized as "light" ( $<20 \mathrm{bpm})$, "moderate" (20-30 bpm) and "heavy" (> $30 \mathrm{bpm}$ ) (Figure 5). Carrying objects of different weights in forced and uncomfortable body positions is reflected in high strain. It is worth noting that in 9 out of 23 work-processes the work pulse exceeded the recommended limit of work related strain (i.e., $\Delta \mathrm{HR}>30 \mathrm{bpm}$ ) and that the total time spent in this work intensity spans over about $5 \mathrm{~h}$, exceeding $60 \%$ of the shift. Some of these work processes are illustrated in Movies 1-4 (for further details, consult the legend to Figure 5).

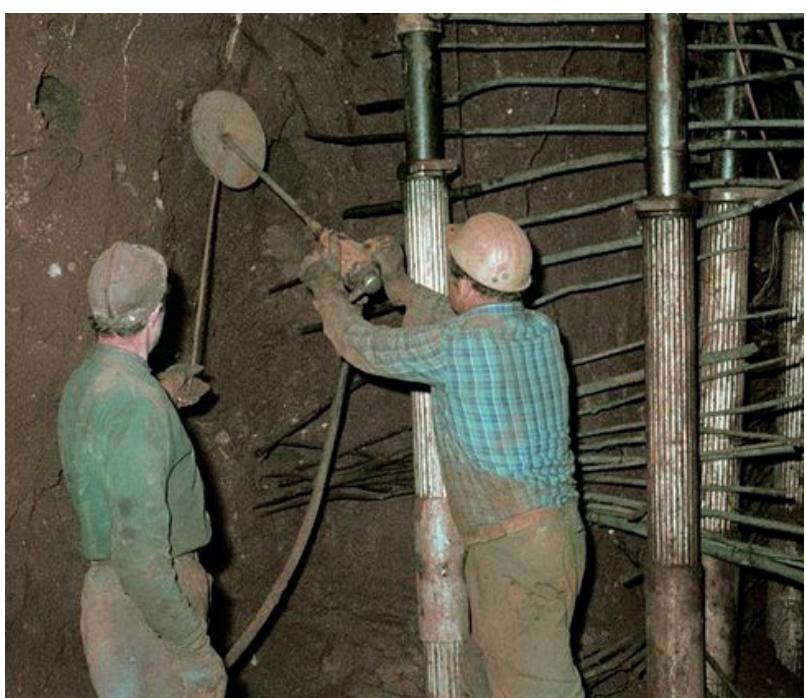

The drilling bit runs through a metal plate that is pressed against the wall by a 2 nd miner for dust-prevention purposes.

Photo 1. Drilling in bauxite with pneumatic drill 


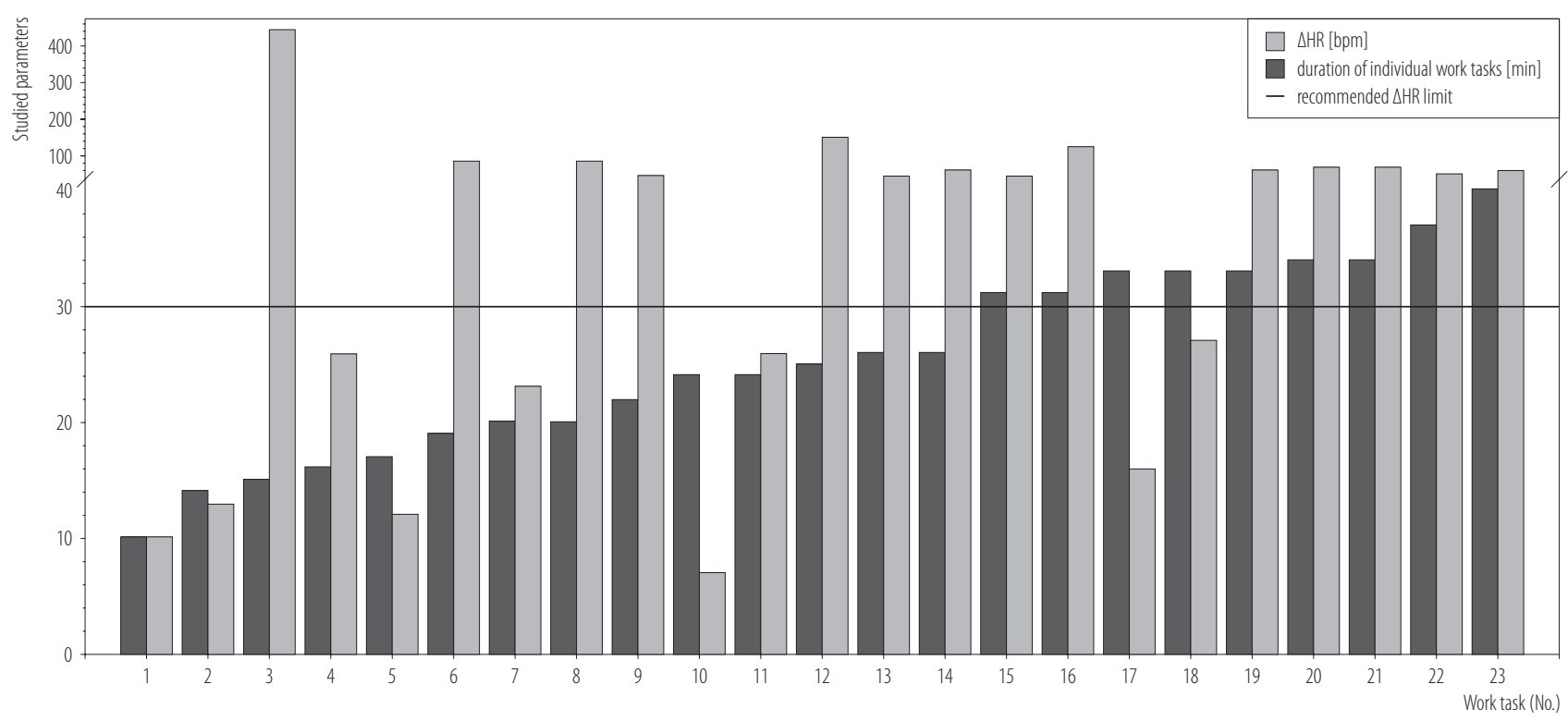

Work tasks:

- light: 1 - entering the mine; 2 - leaving off; 3 - drilling with drilling cart; 4 - waiting on surface; 5 - preparation and cessation; 6 - haulage of dead ground; 7 - waiting for smoke after blasting; 8 - building provisional wooden support;

- moderate: 9 - trouble-shooting; 10 - blasting; 11 - screw on TH arcs; 12 - maintaining the hauling routes; 13 - manual transportation of dead ground; 14 - building additional support using TH arcs;

- heavy: 15 - drilling cart preparation; 16 - stoping with pneumatic pick; 17 - drilling machine preparation, 18 - conveying supporting materials; 19 - comminution of ore in runways using pneumatic pick; 20 - aligning with pneumatic pick and installing provisional support; 21 - stoping with pneumatic pick - installing permanent support; 22 - conveying and filling-in explosives; 23 - drilling with manual machines.

Examples in movies:

- work task No. 10 - filling explosive in bore-hole [20] - worker results: $\Delta \mathrm{HR}=25 \mathrm{bpm}, \mathrm{HR}=99 \mathrm{bpm}$;

- work task No. 16 - break with pneumatic pick-hammer [21] - worker results: $\Delta \mathrm{HR}=32 \mathrm{bpm}, \mathrm{HR}=105 \mathrm{bpm}$;

- work task No. 18 - building roof support [22] - worker results: $\Delta \mathrm{HR}=35 \mathrm{bpm}, \mathrm{HR}=109 \mathrm{bpm}$;

- work task No. 23 - drilling in bauxite mine with pneumatic drill [23] - worker results: $\Delta \mathrm{HR}=40 \mathrm{bpm}, \mathrm{HR}=112 \mathrm{bpm}$.

Fig. 5. Work pulse $(\Delta \mathrm{HR})$ and duration of work tasks based on 124 shifts of 15 miners

\section{Impact of psychological and physical factors} on the cardiovascular responses

Data in Table 2, and Figures 2 and 3 clearly demonstrate that there is an appreciable difference between the physiological strain as measured directly by recorded absolute heart rate and the work pulse among workers in the same workplace. These differences cannot entirely be accounted for by the effects only of physical work itself. Elements of complex stress during physical work appear together and the combined effects contribute to the strain of the organism. There is no purely physical or purely psychological stress; there are predominantly physical or psychological effects. When examining the strain of the human organism, the combined effects of stress are relevant.

\section{Examining complex strain by the effects}

of simulated danger situation in the mine

The complex nature of work stress and the changes of the physiological strain of the human organism are demonstrated by analyzing examples in the following situations: creating simulated danger in the mine; stress effects 
of the instruments used to record physiological variables; the effects of changing the illumination of the workplace and the presence of managers (mainly in morning shifts). We simulated danger situation in the mine by producing sham danger situations in which the affected miners were not aware whether the alarm was triggered artificially or by real danger situation. In this situation the miners in the affected area wore self-rescuing breathing apparatus with CO filter (SZPP-2, USSR). As control situation, we repeated the measurements on the next day but without the alarm situation during leaving the mine using the same escape route and wearing the same self-rescue apparatus. During the sham alarm period, the mean work pulse was $36.7 \pm 4.8 \mathrm{bpm}$, while during normal working conditions and exiting the mine without alarm it was $25.8 \pm 1.6 \mathrm{bpm}$ and $21.7 \pm 3.3 \mathrm{bpm}$, respectively, both being below the recommended limit of $30 \mathrm{bpm}$ (Figure 6). The difference between the work pulse while leaving the mine during the sham alarm and without alarm can be accounted for by the psychological stress (i.e., about $15 \mathrm{bpm}$ ).

Based on the estimated energetic equivalents, the average increase in heart rate would be about 22-30 bpm work pulse. It is apparent that on average, this group of 6 miners exceeded

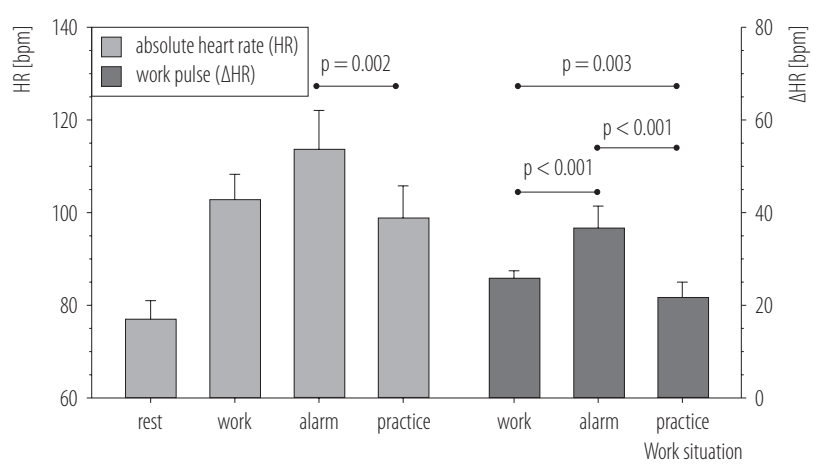

Mean \pm standard deviation, RM ANOVA on ranks.

Fig. 6. Effects of sham alarm situation (alarm) on the physiological strain compared to normal working conditions (work) and exiting the mine while wearing the same self-rescue apparatus but without alarm situation (practice) 6 miners working under the same conditions appreciably the mean value characteristic for the normal work shift and approached the values registered during the heaviest work processes. From these results the pure effect of the additional psychological stress from the alarm situation can easily be estimated. Notably, the total time of escape from the alarm until getting out of the mine was $34 \mathrm{~min}$, while the first 14 min were considered as dangerous. It is also remarkable that when the feeling of danger was over, the parameters measured during the use of the self-rescue breathing apparatus were nearly similar to those measured during an earlier practice period without danger.

\section{Effects of psychological factors - impact of "instrument stress" on work-related strain}

During the first day of instrumental observations we noted consistently higher work pulse values than on other days. The degree of this "instrument stress" is reflected by the difference in the results between the first day and the values recorded on other days. This increase was about $9 \%$ and was observable only during the first day of observation. The difference both in heart rate and in work pulse were statistically significant (Table 3 , section A). The inter-individual differences were about $\pm 15 \%$.

\section{Effect of the presence of managers}

Typical feature of the morning shifts is the usual presence of managers of different levels. In order to analyze that effect, we separated the morning shifts and compared the results with those of the other two shifts (afternoon and night). The effect of the managerial presence was reflected in an additional increase in heart rate. The presence of managers caused about a $20 \%$ increase in work pulse. The differences are statistically significant (Table 3 , section B).

\section{Relationship between accidents and physiological strain}

Work in the mine involves risk of accidents. There are references in the literature to the relationship between the effects of accidents on physiological strain [25]. Therefore, 
Table 3. Impact of different forms of additional psychological stress on heart rate and work pulse

\begin{tabular}{|c|c|c|}
\hline Type of effect & $\begin{array}{c}\mathrm{HR} \\
{[\mathrm{bpm}]} \\
(\mathrm{M} \pm \mathrm{SD})\end{array}$ & $\begin{array}{c}\Delta \mathrm{HR} \\
{[\mathrm{bpm}]} \\
(\mathrm{M} \pm \mathrm{SD}) \\
\end{array}$ \\
\hline \multicolumn{3}{|l|}{ A. Impact of instrument stress on physiological strain } \\
\hline 1st day observation $(\mathrm{N}=15)$ & $110 \pm 12$ & $30 \pm 11$ \\
\hline 2nd-10th days observations $(\mathrm{N}=110)$ & $104 \pm 11^{*}$ & $26 \pm 9 *$ \\
\hline \multicolumn{3}{|l|}{ B. Impact of the presence of managers } \\
\hline morning shifts $(\mathrm{N}=70)$ & $112 \pm 12$ & $29 \pm 10$ \\
\hline afternoon and night shifts $(\mathrm{N}=55)$ & $102 \pm 10 * *$ & $23 \pm 8^{* *}$ \\
\hline \multicolumn{3}{|c|}{ C. Physiological strain in accident sufferers vs. accident-free subjects } \\
\hline frequently involved in accidents $(\mathrm{N}=33)$ & $111 \pm 13$ & $34 \pm 10$ \\
\hline not previously involved in accidents $(\mathrm{N}=13)$ & $101 \pm 9^{* *}$ & $29 \pm 5^{* *}$ \\
\hline
\end{tabular}

$\mathrm{N}$ - in sections A and B: total number of shifts; in section C: number of workers observed. Other abbreviations as in Table 2.

$* \mathrm{p}<0.05 ; * \mathrm{p}<0.01$.

we analyzed the differences in physiological strain between workers frequently involved in accidents and those not involved. These studies were conducted in an underground coal-mine and the results are summarized in section $\mathrm{C}$ of Table 3. In general, the work pulse of workers frequently involved in work-related accidents was $17 \%$ higher than in those who were accident-free $(\mathrm{p}<0.01)$.

\section{Impact of the illumination level on work-related strain}

In a series of 70 measurements, the level of illumination of the workplace (drift work) was 15-20 Lux in accordance with the general practice. In order to analyze the effects of illumination we nearly doubled the illumination and this level was maintained for the next 55 work shifts. The elevated illumination at work places was between 36-45 Lux. The effects of this "better" illumination on the work pulse while performing the same work activities are demonstrated in Figure 7. The boxes illustrate both heart rate and work pulse values of 15 subjects during 70 shifts at usual illumination levels and during 55 shifts at elevated level of illumination. Both difference in heart rate and work pulse were remarkable and statistically significant (Figure 7). When the illumination level was high, the physiological

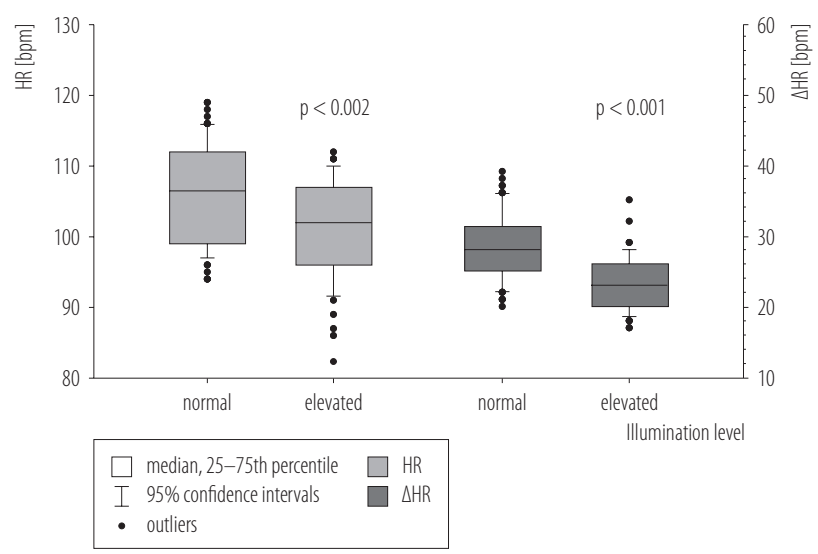

P values according to rank sum test by Mann-Whitney U statistic.

Fig. 7. Effect of illumination on heart rate (HR) and work pulse $(\Delta \mathrm{HR})$ of 15 miners with 70 shifts under normal illumination and 70 miners with 55 shifts under elevated illumination

strain during the same work activity decreased significantly; both absolute heart rate and the work pulse decreased by $5-18 \%$ ( $p<0.002$ and $p<0.001$ ), respectively.

\section{DISCUSSION}

The results presented in this report were collected over a vast number of observations on numerous workers in several underground mines in Hungary 
between 1987 and 1992. At the time of these observations, the mining industry was still significant in the economy. We believe that the results are still relevant in several aspects. We have shown, using direct physiological observations under real working conditions in the mines that it is not only the physical work and the intensity of it that contribute to the physiological strain as measured by work pulse, but there are several other, mainly psychological factors contributing to an additional cardiovascular strain of workers.

Moreover, these observations were unique at the time in Hungary and in some aspects we believe are still novel. These data are unique in the international literature as the information on the practical approaches using physiological measurements cover mainly experimental conditions $[10,14]$ and very few are based on measurements under real working conditions [26-28], particularly in hot environment [29]. Ever since these early observations, we have used the same methodology in other industrial branches successfully (unpublished data).

We aimed at assessing the physiological strain of workers under real-life conditions while minimizing the disturbance caused by the presence of managers, instruments and special instructions, although we have also shown that these effects are significant (see sections: Effects of psychological factors - impact of "instrument stress" on work-related strain, and Effect of the presence of managers).

We concluded that the most reliable information characterizing human strain is the value of heart rate increment (i.e., the work pulse, or $\Delta \mathrm{HR}$ ); thus, in the workplace it is sufficient to measure heart rate and consider only the work-related increment. It is advantageous that out of all physiological parameters, heart rate is the simplest and the safest to measure. Although, we also demonstrated that along with significant increases in heart rate, the body core temperature is also increasing and often exceeds the recommended limits. This phenomenon might be highly relevant in workplaces with elevated temperatures or under conditions inhibiting heat dissipation.

Carrying objects of different weights in forced and uncomfortable body positions is reflected in high strain. These results (Figure 5) are also in agreement with other publications $[27,30,31]$. There is a need to implement technical modernization of certain manual work-intensive processes; besides, introduction of work organization measures might be necessary.

Our results show that complex work-related stress is affected not only by physical activities but also by mental and psychological factors and the heart rate increment is suitable to describe these complex effects. Several papers have recently been published [32-36] on widening the scope and importance of complex work stress, which increasingly justify the application of instrumental physiological measurements and the importance of examining these problems. Studying the strain of the human organism associated with work activities requires complex methods, including physiological measurements. Development of national programs is needed for long term application of such methods in ergonomics and work physiology [37]. The data presented in Table 2 demonstrate the significant differences in the individual mean work-related strain among miners working in drift drilling. These differences demonstrate that improvements of mining technologies and work organization might be necessary in order to minimize the detrimental effects of work-related physiological strain.

We found that during sham-alarm situations the physiological strain increases. It is remarkable how much the sensation of danger alone can contribute to the increase in heart rate. Use of self-rescue breathing apparatus in experimental situations has been described [38], but not in real life during simulated alarm in regular work-shift.

We have also shown that the improvement of illumination of work places by about two times decreases the physiological strain by about $18 \%$. This lessening of strain may 
have perceptible consequences on the circulatory system cumulatively over several decades of exposure and might decrease the effect of the work-related cardiovascular risk factor. Our results are in agreement with other examples in the literature that showed similar reduction in physiological strain due to better illumination at workplaces $[39,40]$. In addition to the demonstrated examples (Figures 6, 7 and Table 3 ) the complex nature of strain is also confirmed in the literature $[27,31,39,41]$.

In a unique analysis we have shown that those workers who were frequently involved in accidents, experienced greater physiological strain compared to those without history of accidents. The real question is whether the increased strain is caused by a certain level of "fear" at work, or workers showing greater physiological strain are more prone to accidents. We were unable to answer this question and more observations and research would be needed in this regard. Certainly, the effects of age and lifestyle (hypertension, smoking and body mass) might have influenced the results.

In addition to the various physical and psychological effects in the mines, different mining technologies may also result in potentially changing requirement for manual work and may have different requirements of attention and psychological involvement as well. These will lead to differences in work pulse and the overall physiological strain. We found (data not presented) that the smallest strain is represented by a well-mechanized mine with diesel machinery and light-metal supporting technology. As more manual work is involved (e.g., drift drilling through dead rock and mixed section rock), it is natural that HR and the work pulse are appreciably higher.

Finally, it has been shown in a large-scale screening study that intense physical work, such as mining, might present a unique risk factor for cardiovascular diseases $[18,19]$. Taking all these together, it seems that reducing the physiological strain by improving work organization and technology might result in a decrease in overall cardiovascular morbidity.

\section{Limitations}

The subjects participating in the workplace measurements did not take part in clinical laboratory examinations but they completed incremental exercise tests in the laboratory. In the first period of workplace measurements (19871992), as a result of our inexperience due to the novelty of the procedures, we did not analyze effects of essential influential factors like age, life-style (hypertension, smoking, body mass), private life (work, entertainment, family circumstances) or meso- and macro-effects of the particularities of the mine or the broader environment. In the second period of our measurements we took all these factors into consideration when planning our examinations.

\section{CONCLUSIONS}

Our data clearly show that complex estimation of physiological strain is advantageous compared to methods based on energetic estimation only. This latter one cannot take into account the characteristics of the individual and the work environment (climatic conditions, noise and illumination levels), and those arising from work organizational effects (night shift or shift work in general, or the length of the shift), nor the psychological effects of the micro-, meso- or macro-society. It is also important to note that recording heart rate during real work conditions is no more a technological obstacle and does not need costly investment, therefore the cost effectiveness of similar studies is in the affordability range on a much larger scale than it is used currently. These measurements will be of value in planning and implementing ergonomic interventions describing work stress and complex strain in order to decrease the risk factors associated with heavy physical work.

\section{ACKNOWLEDGMENTS}

We would like to thank the Committee on Mining Health and Safety of the Hungarian Academy of Sciences for providing a forum to discuss partial results of our research and supporting 
our substantial work by providing critical review. We are also thankful to the managers of the companies and mines for creating appropriate conditions for our measurements, to the operating specialists for their help in organizing and to the workers for participating in these novel experimental measurements and for their partnership in the finalization of the measurement methods.

We would like to dedicate this paper to the memory of Professor Szilárd Donhoffer, a member of the Hungarian Academy of Sciences, who established the first physiological measurements in the mines and dedicated a laboratory at University Medical School of Pécs to study the lung function of miners; and Professor Theodor Hettinger (Mühlheim, Germany), who stimulated the realization of these research ideas.

\section{REFERENCES}

1. Hettinger T. [Measurement methods in work physiology]. 2nd ed. Berlin: Beuth; 1965. German.

2. Hettinger T. [Applied ergonomics]. Frechen: Bartmann; 1970. German.

3. Lehmann G. [Handbook of occupational medicine. Vol. 1. Work physiology]. Munich: Urban and Schwarzenberg; 1961. German.

4. Spitzer H, Hettinger T. [Tables for determination of energy consumption of full-body exercise]. Darmstadt: Beuth Verlag; 1964. German.

5. International Organization for Standardization. Ergonomics - Determination of metabolic heat production. Geneva: The Organization; 1990.

6. Ainsworth BE, Haskell WL, Leon AS, Jacobs DR Jr., Montoye HJ, Sallis JF, et al. Compendium of physical activities: Classification of energy costs of human physical activities. Med Sci Sports Exerc. 1993;25(1):71-80, http://dx.doi. org/10.1249/00005768-199301000-00011.

7. Borg G. A category scale with ratio properties for intermodal and individual comparisons. Psychophysical Judgment and the Process of Perception. Amsterdam: North-Holland Publishing Company; 1982.
8. Hettinger T. [Methods for detection of load and the stress and strain of the people in the world of work]. In: Krause H, Pillat R, Zander E, editors. [Work safety]. Freiburg: Haufe; 1981. p. 832-41. German.

9. Hettinger T, Averkamp C, Müller BH. [Working conditions in the glass industry. Volume 1: Methods and techniques of ergonomic field studies]. Berlin/Köln: Beuth Verlag; 1987. German.

10. Garg A, Banaag J. Maximum acceptable weights, heart rates and RPEs for one hour's repetitive asymmetric lifting. Ergonomics. 1988;31(1):77-96, http://dx.doi. org/10.1080/00140138808966650.

11. Hettinger T, Nesper-Klumpp U. [The pulse rate as a criterion for evaluation of physical stress]. Z Arbeitswiss. 1981;35:235. German.

12. Johansson S-E, Borg G. Perception of heavy work operations by tank truck drivers. Appl Ergon. 1993;24(6):421-6, http://dx.doi.org/10.1016/0003-6870(93)90174-8.

13. Strasser H. [Ergonomic methods of stress determination: Stress profiles in terms of feasibility and tolerability of human labor]. Stuttgart: Gentner; 1982. German.

14. Kodak's ergonomic design for people at work. Vol 2. Eastman Kodak Company. New York: John Wiley \& Sons; 1986 [cited 2015 Jan 12]. Available from: http://onlinelibrary. wiley.com/doi/10.1002/9780470172469.fmatter/pdf.

15. Beach JR, de Klerk NH, Fritschi L, Sim MR, Musk AW, Benke $\mathrm{G}$, et al. Respiratory symptoms and lung function in bauxite miners. Int Arch Occup Environ Health. 2001;74(7): 489-94, http://dx.doi.org/10.1007/s004200100245.

16. DeKom JFM, Dissels HMH, van DerVoet GB, de Wolff FA. Serum aluminium levels of workers in the bauxite mines. Clin Toxicol. 1997;35(6):645-51, http://dx.doi. org/10.3109/15563659709001248.

17. Kovács T. Thoron measurements in Hungary. Radiat Prot Dosimetry. 2010;141(4):328-34, http://dx.doi.org/10.1093/ $\mathrm{rpd} / \mathrm{ncq} 232$.

18. Fenyvesi E, Pórszász J, Simor T. Evaluation of ischemic heart disease and its primary risk factors by ergometric 
studies at the Mecsek Ore Mining Company. Orv Hetil. 1988;129(3):135-40.

19. Pórszász J, Sárdi F, Kovács S. Cardiovascular risk factors and physical fitness. A review of screening of a large population of physical workers in Pécs. Cent Eur J Occup Environ Med. 1995;1(3):252-61.

20. Varga J. Filling explosive in bore-hole. 2015 Jul 6 [cited 2016 May 23]. In: Youtube.com [Internet]. Available from: http:// youtu.be/1JkE6UutZDE.

21. Varga J. Break with pneumatic pick-hammer. 2015 Jul 6 [cited 2016 May 23]. In: Youtube.com [Internet]. Available from: http://youtu.be/paVTyyb3XUg.

22. Varga J. Building roof support. 2015 Jul 6 [cited 2016 May 23]. In: Youtube.com [Internet]. Available from: http:// youtu.be/xhS1Uo2mNfg.

23. Varga J. Drilling in bauxite mine with pneumatic drill. 2015 Jul 6 [cited 2016 May 23]. In: Youtube.com [Internet]. Available from: http://youtu.be/B5xzmUch_i4.

24. Bruce RA, Kusumi F, Hosmer D. Maximal oxygen intake and nomographic assessment of functional aerobic impairment in cardiovascular disease. Am Heart J 1973;85(4): 546-62, http://dx.doi.org/10.1016/0002-8703(73)90502-4.

25. Burgess-Limerick R, Steiner L. Injuries associated with continuous miners, shuttle cars, load-haul-dump and personnel transport in New South Wales underground coal mines. Min Technol. 2006;115(4):160-8, http://dx.doi.org/10.1179/174328606X151033.

26. Kenny GP, Vierula M, Maté J, Beaulieu F, Hardcastle SG, Reardon F. A field evaluation of the physiological demands of miners in Canada's deep mechanized mines. J Occup Environ Hyg. 2012;9(8):491-501, http://dx.doi.org/10.1080/ 15459624.2012.693880.

27. Saha R, Dey NC, Samanta A, Biswas R. A comparative study of physiological strain of underground coal miners in India. J Hum Ergol. 2007;36:1-12.

28. Saha R, Dey NC, Samanta A, Biswas R. A comparison of cardiac strain among drillers of two different age groups in underground manual coal mines in India. J Occup Health. 2008;50(6):512-20, http://dx.doi.org/10.1539/joh.07005.
29. Kalkowsky B, Kampmann B. Physiological strain of miners at hot working places in German coal mines. Ind Health. 2006;44(3):465-73, http://dx.doi.org/10.2486/ind health.44.465.

30. Bhattacharya A, Succop P, Kincl L, Gordon J, Sobeih T. Postural stability associated with restricted ceiling height mining tasks. Occup Ergon. 2009;8(2):91-114.

31. Gallagher S. Acceptable weights and physiological costs of performing combined manual handling tasks in restricted postures. Ergonomics. 1991;34(7):939-52, http://dx.doi.org/ 10.1080/00140139108964836.

32. Burdorf A. The need for novel strategies to analyze the dynamic pattern of worker's health over time and the consequences for sustained employability. Scand J Work Environ Health. 2012;38(6):485-8, http://dx.doi.org/10.5271/ sjweh.3325.

33. Kristensen P, Aalen OO. Understanding mechanisms: Opening the "black box" in observational studies. Scand J Work Environ Health. 2013;39(2):121-4, http://dx.doi.org/ 10.5271/sjweh.3343.

34. Neumann WP, Dixon S, Ekman M. Ergonomics action research I: Shifting from hypothesis testing to experiential learning. Ergonomics. 2012;55(10):1127-39, http://dx.doi. org/10.1080/00140139.2012.700327.

35. Sengupta AK, Das B. Determination of worker physiological cost in workspace reach envelopes. Ergonomics. 2004;47(3):330-42, http://dx.doi.org/10.1080/001401303200 0157850 .

36. Stansfeld S, Candy B. Psychosocial work environment and mental health - A meta-analytic review. Scand J Work Environ Health. 2006;32(6):443-62, http://dx.doi.org/10.5271/ sjweh.1050.

37. Ilmarinen J. Towards a longer and better working life: A challenge of work force ageing. Med Lav. 2005;97(2):143-7.

38. Kamon E, Doyle D, Kovac J. The oxygen cost of an escape from an underground coal mine. Am Ind Hyg Assoc J 1983;44(7):55-5, http://dx.doi.org/10.1080/1529866839 1405292. 
39. Hoffmann G, Gufler V, Griesmacher A, Bartenbach C, Canazei M, Staggl S, et al. Effects of variable lighting intensities and colour temperatures on sulphatoxymelatonin and subjective mood in an experimental office workplace. Appl Ergon. 2008;39(6):719-28, http://dx.doi.org/10.1016/ j.apergo.2007.11.005.
40. Karwovsky W, Marras W, editors. The occupational ergonomics handbook. Boca Raton, London, New York, Washington: CRC Press; 1999.

41. Bhattacharya A, McGlothlin J. Occupational ergonomics: Theory and applications. New York: Marcel Dekker, Inc; 1996.

This work is available in Open Access model and licensed under a Creative Commons Attribution-NonCommercial 3.0 Poland License - http://creativecommons.org/ licenses/by-nc/3.0/pl/deed.en. 